https://www.journal-imab-bg.org

Original article
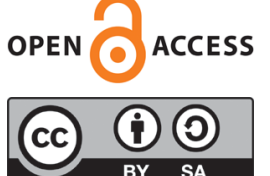

\section{COMPARATIVE STUDY OF THE FREQUENCY OF TOOTH BRUSHING IN PATIENTS WITH PROSTHETIC RESTORATIONS AND IN HEALTHY CONTROLS}

\author{
Anna Nenova-Nogalcheva ${ }^{1}$, Desislava Konstantinova ${ }^{2}$, Petia Pechalova ${ }^{3}$ \\ 1) Department of Oral Surgery, Medical University - Varna, Bulgaria. \\ 2) Department of Dental Materials Science and Propedeutics of Prosthetic \\ Dental Medicine, Medical University - Varna, Bulgaria. \\ 3) Department of Oral Surgery, Medical University - Plovdiv, Bulgaria.
}

\begin{abstract}
:
The main criterion for personal oral hygiene is the frequency of daily effective tooth brushing.

The aim of the study is to establish any differences in the frequency of tooth brushing in patients with dental prostheses and in healthy controls.

Materials and methods: The study was based on the informed, voluntary participation of 140 dental patients from the North-East of Bulgaria, who were divided into 2 groups, each comprising 70 individuals: a Group of patients with removable and/or fixed dentures and a Control Group including healthy volunteers without any missing or restored teeth. The patients were further divided into two Age groups: 19 - 32 year-olds (Young Age) and 33 - 90 yearolds (Middle age, Adults and Elderly).

Results: The mean age of the subjects included in the study was 43.5 years. The Control Group consisted of 19-year-old adolescents, and the group of patients with prosthetic constructions involved individuals aged 22 - 90 years (mean age 53.14 years, $\mathrm{SD}=17.48$ ). The participants in the Control Group tend to perform a more frequent tooth brushing as opposed to those in the Group of patients with dental prostheses $(\mathrm{U}=628.500, \mathrm{p}=0.000)$. Under the age of 32 are $15.70 \%$ of the patients with prosthetic constructions who brush their teeth once a day. The highest percentage $(60 \%)$ of participants who brush their teeth once a day is represented by middle-aged and adult individuals, followed by patients brushing their teeth twice a day who are also of the same age group (24.30\%).
\end{abstract}

Conclusion: The frequency of oral care is poor in patients with a prosthetically restored masticatory apparatus (up to once daily) compared to healthy volunteers. prosthesis

Keywords: oral hygiene, tooth brushing, dental

Oral hygiene proves to be a significant factor in maintaining good oral health and self-esteem. In ancient times, various means of sustaining oral hygiene were known and applied, such as herbs, bones, minerals, etc. The ancient Greeks used toothpicks to clean their teeth. [1]
Chewing different kinds of resin were also practised for cleaning and bleaching the teeth. Rinsing the mouth with wine, milk and in combination with bee products was widely recommended. In 1500 B.C., Egyptians used a mixture of natural clay, incense and other ingredients as a toothpaste. [2, 3] Around 1000 B.C., toothbrushes were found to be used in China. Hippocrates (440 - 377 B.C.) recommended the use of toothpaste made from ground plant roots, mastic resin and ammonium acid. For several centuries, bone ash was also used for the purpose. In his "Natural History" Pliny the Elder (23-79 AD) described many recipes for dentifrice (powders and pastes) based on various mineral abrasives used as cleaning agents. Among the main products present in those dentifrices were eggshell powder, coral powder, pearl powder, Balsam of Peru, mastic resin, bee products, wine, milk, salt, talcum powder, parts of various plants, etc. In the mid-9th century, the Arabian physician Regis recommended the use of tooth powder comprised of 5\% black pepper content. [4] In 15thcentury Italy, the practice of teeth cleaning included the use of cooking salt. [5] It was not until the 16th - 17th century that a tendency started to develop towards a more widespread application of oral hygiene, accessible not only to people from privileged rich backgrounds. [6] As a result of the advance in various sciences, toothpastes and mouthwashes appeared. In less than 100 years, the growth of some applied and fundamental sciences, as well as the development of effective oral hygiene machines and devices, led to the high level of dentifrice production. [7] Initially, the simpler compositions were elaborated and refined to include active substances, antiseptics, preservatives, stabilizers, etc. By the end of the 20th century, many pastes were created for the purpose of oral hygiene, and the recipes and tests for their physicochemical and clinical properties had been improved. Nowadays, the main criterion for personal oral hygiene is the frequency of daily effective tooth brushing.

The aim of the present study is to establish any differences in the frequency of tooth brushing in patients with dental prostheses and in healthy controls. 


\section{MATERIALS AND METHODS}

The study was based on the informed, voluntary participation of 140 dental patients from the North-East of Bulgaria, who were divided into 2 groups, each comprising 70 individuals: a Group of patients with removable and/ or fixed dentures and a Control Group including healthy volunteers without any missing or restored teeth. In our previous studies [16], it was statistically proven that patients' age affects all anatomical, physiological and morphological structures. For the purpose of the present study, the patients were therefore further divided into two Age groups: 19 - 32 year-olds (i.e. in Young Age as per WHO Classification) and 33 - 90 year-olds (Middle age, Adults and Eld- erly as per WHO Classification). Data was collected involving details of the medical history, socio-demographic characteristics, including the patients' gender, age, dental care habits, etc.

\section{RESULTS:}

The subjects included in the study were aged 19 90 years (mean age 43.5 years). The Control Group consisted of 19-year-old adolescents, and the group of patients with prosthetic constructions involved individuals aged 22 - 90 years (mean age 53.14 years, $\mathrm{SD}=17.48$ ). The distribution of participants, according to age is presented in Table 1 .

Table 1. Age distribution of patients

\begin{tabular}{|c|c|c|c|c|c|c|}
\hline \multirow{3}{*}{ Age } & \multicolumn{4}{|c|}{ Groups } & & \\
\hline & \multicolumn{2}{|c|}{ Control group } & \multicolumn{2}{|c|}{$\begin{array}{l}\text { Group of patients with } \\
\text { prosthetic constructions }\end{array}$} & \multicolumn{2}{|c|}{ Total } \\
\hline & number & $\%$ & number & $\%$ & number & $\%$ \\
\hline 19-32 years old & 70 & 100 & 11 & 15.7 & 81 & 57.9 \\
\hline 33-90 yearsold & 0 & - & 59 & 84.3 & 59 & 42.1 \\
\hline
\end{tabular}

The distribution of participants according to their gender is presented in Table 2.

Table 2. Gender distribution of patients

\begin{tabular}{|c|c|c|c|c|c|c|}
\hline \multirow[t]{3}{*}{ Gender } & \multicolumn{4}{|c|}{ Groups } & \multirow{2}{*}{\multicolumn{2}{|c|}{ Total }} \\
\hline & \multicolumn{2}{|c|}{ Control group } & \multicolumn{2}{|c|}{$\begin{array}{l}\text { Group of patients with } \\
\text { prosthetic constructions }\end{array}$} & & \\
\hline & number & $\%$ & number & $\%$ & number & $\%$ \\
\hline Men & 39 & 55.7 & 38 & 54.3 & 77 & 55 \\
\hline Women & 31 & 44.3 & 32 & 45.7 & 63 & 45 \\
\hline Total & 70 & 100 & 70 & 100 & 140 & 100 \\
\hline
\end{tabular}

The data obtained on the frequency of tooth brushing is presented in Table 3 . There is a statistically significant difference $(\mathrm{U}=628.500, \mathrm{p}=0.000)$ between patients in both groups under study regarding the frequency of teeth cleaning. The participants in the Control Group tend to perform a more frequent tooth brushing as opposed to those in the Group of patients with dental prostheses. In the Control Group, accounting for the largest percentage are the male patients who brush their teeth twice daily
(27.10\%), followed by men who brush their teeth 3times a day $(21.40 \%)$. Among the female, patients there is an apparent even distribution between those who brush their teeth twice and three times a day (20\%). In patients with prosthetic constructions, the highest percentage is represented by men who brush their teeth once a day (41.40\%), followed by women who perform that activity once a day $(34.30 \%)$. No patients with prosthetic constructions are found to clean their teeth and dentures three times a day.

Table 3. Daily frequency of tooth brushing in patients from both groups, distributed according to gender

\begin{tabular}{|c|c|c|c|c|c|c|c|c|c|c|c|c|}
\hline \multirow{4}{*}{$\begin{array}{c}\text { Daily tooth } \\
\text { brushing }\end{array}$} & \multicolumn{12}{|c|}{ Groups } \\
\hline & \multicolumn{6}{|c|}{ Control Group } & \multicolumn{6}{|c|}{ Patients with prosthetic constructions } \\
\hline & \multicolumn{2}{|c|}{ Men } & \multicolumn{2}{|c|}{ Women } & \multicolumn{2}{|c|}{ Total } & \multicolumn{2}{|c|}{ Men } & \multicolumn{2}{|c|}{ Women } & \multicolumn{2}{|c|}{ Total } \\
\hline & number & $\%$ & number & $\%$ & number & $\%$ & number & $\%$ & number & $\%$ & number & $\%$ \\
\hline 1 time & 5 & 7.1 & 3 & 4.3 & 8 & 11.4 & 29 & 41.4 & 24 & 34.3 & 53 & 75.7 \\
\hline 2 times & 19 & 27.1 & 14 & 20 & 33 & 47.1 & 9 & 12.9 & 8 & 11.4 & 17 & 24.3 \\
\hline 3 times & 15 & 21.4 & 14 & 20 & 29 & 41.4 & 0 & - & 0 & - & 0 & - \\
\hline
\end{tabular}


The frequency of tooth brushing appears to be quite interesting across age for both groups. (Table 4) $15.70 \%$ of the patients with prosthetic constructions who brush their teeth once a day is under the age of 32 . The highest per- centage $(60 \%)$ of participants who brush their teeth once a day is represented by middle-aged and adult individuals, followed by patients brushing their teeth twice a day who are also of the same age group (24.30\%).

Table 4. Frequency and percentage distribution of daily frequency of tooth brushing according to age and group

\begin{tabular}{|c|c|c|c|c|c|c|c|c|c|c|c|c|}
\hline \multirow{4}{*}{$\begin{array}{c}\text { Daily tooth } \\
\text { brushing }\end{array}$} & \multicolumn{12}{|c|}{ Groups } \\
\hline & \multicolumn{6}{|c|}{ Control Group } & \multicolumn{6}{|c|}{ Patients with prosthetic constructions } \\
\hline & \multicolumn{2}{|c|}{ 19-32 years old } & \multicolumn{2}{|c|}{ 33-90 years old } & \multicolumn{2}{|c|}{ Total } & \multicolumn{2}{|c|}{ 19-32 years old } & \multicolumn{2}{|c|}{ 33-90 years old } & \multicolumn{2}{|c|}{ Total } \\
\hline & number & $\%$ & number & $\%$ & number & $\%$ & number & $\%$ & number & $\%$ & number & $\%$ \\
\hline 1 time & 8 & 11.4 & 0 & - & 8 & 11.4 & 11 & 15.7 & 42 & 60.0 & 53 & 75.7 \\
\hline 2 times & 33 & 47.1 & 0 & - & 33 & 47.1 & 0 & - & 17 & 24.3 & 17 & 24.3 \\
\hline 3 times & 29 & 41.4 & 0 & - & 29 & 41.4 & 0 & - & 0 & 0 & 0 & 0 \\
\hline
\end{tabular}

\section{DISCUSSION:}

A significant number of patients with various prosthetic constructions wrongly believe that artificial teeth do not need as much diligent care as their own teeth require. Improper care, however, can lead to impairment of the denture's biological base, its stability and, in rare cases, the denture may become completely impossible to use. According to the data collected from the healthy controls, tooth brushing takes place after each meal (29 patients, $41.40 \%$ ), and twice a day in almost half of the respondents (47.10\%). The participants in the Control Group are young people (19 year-olds) who are conscious of their appearance and personal hygiene. In addition to its preventive effect in the long run, the overall maintenance of good oral hygiene, sometimes not readily seen by the patient, has a cosmetic effect which becomes apparent to the patient even during the process of brushing. The benefits from this activity are removal of nutritional residues, removal of plaque, inhibition of calculus accumulation, the freshness of mouth and breath, removal of the coloured dental pellicle, etc. A number of authors claim that there is a link between age and the onset of diseases of the masticatory apparatus that can be managed by observing good oral hygiene. $[9,10]$

The frequency of oral care is poor in patients with a prosthetically restored masticatory apparatus (up to once daily). After the initial joy and comfort from having restored dentitions, such patients tend to strictly adhere to the instructions for personal oral hygiene at first and then gradually start to neglect them. The dental materials used for the fabrication of the prosthetic constructions also contribute to their good upkeep. Therefore, O'Brien stresses the connection between the choice of dental material for the prosthetic construction and the subsequent care for the denture provided the patient is willing and well of aware of the importance of brushing it. Other researchers pay particular attention to the significance of removing the biofilm from the removable prosthetic constructions. [11, 12, 13, 14]

The American Dental Hygienists' Association, devoted to promoting motivation in patients to look after their oral health, has proposed standards for oral hygiene. [8]

There are also other authors who emphasize and prove the correlation between regular oral hygiene routine and good oral health, observed even among patients with prosthetically restored dentitions. [15]

\section{CONCLUSION:}

The frequency of oral care is poor in patients with a prosthetically restored masticatory apparatus (up to once daily) compared to healthy volunteers.

\section{REFERENCES}

1. Shklar G, Carranza F, Williams RC. The historical background of periodontology (1st ed). Chicago, IL, Quintessence Pub Co. 2003; 23-44.

2.Ciancio SG. Chemical Agents: Plaque Control, Calculus Reduction and Treatment of Dentinal Hypersensitivity. Periodontol 2000. 1995 Jun;8:75-86. [PubMed] [Crossref]

3. Jones CG. Chlorhexidine: Is it Still the Gold Standard? Periodontol 2000. 1997 Oct;15:55-62. [PubMed] [Crossref]
4. Darby ML,Walsh M. Dental hygiene theory and practice (1st ed.), Saunders, 1995;4 (2): 99-110

5. Yarde A, Robinson M. The miswak chewing stick: A traditional oral hygiene aid. NDA J. 1996;47:201.

6. Fones AC. The origin and history of the dental hygienists. J Dent Hyg. 2013; 87:58-62

7. Bowen D. History of dental hygiene research. J Dent Hyg. 2013; $87: 5-22$
8. American Dental Hygienists' Association, Standards for Clinical Dental Hygiene Practice. 2008

9. Abdellatif HM, Burt BA. An Epidemiological Investigation Into the Relative Importance of Age and Oral Hygiene Status as Determinants of Periodontitis. J Dent Res. 1987 Jan;66(1): 13-8. [PubMed] [Crossref]

10. Tagge DL, O'Leary TJ, ElKafrawy AH. The Clinical and Histological Response of Periodontal Pockets to Root Planing and Oral Hy- 
giene. J Periodontol. 1975 Sep;46(9): 527-33. [PubMed] [Crossref]

11. Maruniak J, Clark WB, Walker CB, Magnusson I, Marks RG, Taylor M, et al. The Effect of 3 Mouthrinses on Plaque and Gingivitis Development. J Clin Periodontol. 1992 Jan: 19(1):19-23. [PubMed] [Crossref]

13. Smith C. Pigmentation of cosmetics. Manufacturing Chemist,
$1981 ; 52: 24$.

14. Paranhos HF, Salles AE, Macedo LD, Silva-Lovato $\mathrm{CH}$, Pagnano VO, Watanabe E. Complete denture biofilm after brushing with specific denture paste, neutral soap and artificial saliva. Braz Dent J. 2013; 24(1):47-52.

15.de Souza RF, de Freitas Oliveira Paranhos H, Lovato da Silva
CH, Abu-Naba'a L, Fedorowicz Z, Gurgan CA. Interventions for Cleaning Dentures in Adults. Cochrane Database Syst Rev. 2009 Oct 7;(4), CD007395. [PubMed] [Crossref]

16. Konstantinova D. [Examination of the Masticatory Function in Experimental and Clinical Conditions.] [dissertation]. Medical University - Varna. 2016. 56-64 p. [in Bulgarian]

Please cite this article as: Nenova-Nogalcheva A, Konstantinova D, Pechalova P. Comparative Study of the Frequency of tooth brushing in patients with prosthetic restorations and in healthy controls. J of IMAB. 2020 Jan-Mar;26(1):29422945. DOI: https://doi.org/10.5272/jimab.2020261.2942

Received: 10/05/2019; Published online: 25/02/2020

Address for correspondence:

Desislava Konstantinova

Department of Clinic of Prosthetic Dentistry, Medical University - Varna, Bulgaria

84, Tsar Osvoboditelstr., Varna 9000 Bulgaria

E-mail: dr.konstantinova@gmail.com, 